\title{
Miyosen yaşlı Eskigarzan Kireçtaşı Üyesi'nin (Siirt, Güneydoğu Anadolu) bentik foraminiferleri ve paleoortamsal yorum
}

\section{Benthic foraminifers and paleoenvironmental interpretation of the Miocene Eskigarzan Limestone Member (Siirt, Southeast Anatolia)}

\section{Derya SINANOĞLU}

Batman Üniversitesi, Petrol ve Doğalgaz Mühendisliği Bölümü, derya.sinanoglu@batman.edu.tr, Orcid No: 0000-0002-9307-7810

\begin{tabular}{|c|c|}
\hline MAKALE BİLGİLERİ & ÖZET \\
\hline Makale Geçmişi: & $\begin{array}{l}\text { Siirt ili Kurtalan ilçesi civarında yüzeyleyen Miyosen yaşlı karbonatlı çökeller bölgenin jeolojik olarak } \\
\text { değerlendirilmesinde oldukça önem taşır. Bu çalışma, Kayabağlar Formasyonu içerisinde merceksel }\end{array}$ \\
\hline Gelis: 7 Ekim 2021 & olarak yer alan ve Eskigarzan Kireçtaşı Üyesi olarak ayritlanan birimin paleontolojik ve sedimantolojik \\
\hline 3 Kasim 2021 & veriler ışı̆̆ında değerlendirilmesine dayanır. Dört ayrı lokaliteden alınan seri örnekler ile Miyosen yaşlı \\
\hline Kabul: 27 Aralık 2021 & Eskigarzan Kireçtaşı Üyesi'nde: Praebullalveolina curdica (Reichel), Sivasina egribucakensis Sirel ve \\
\hline Available online 31 Aralık 2021 & $\begin{array}{l}\text { Özgen-Erdem, Sivasina batmanensis Sirel, Özgen-Erdem ve Sinanoğlu, Androsina diyarbakirensis Sirel, } \\
\text { Özgen-Erdem ve Sinanoğlu, Cyclorbiculina minima Sirel, Özgen-Erdem ve Sinanoğlu, Amphistegina cf. }\end{array}$ \\
\hline Anahtar Kelimeler: & $\begin{array}{l}\text { targioni Meneghini, Elphidium cf. crispum, Miogypsinoides sp., Rotalia sp., Sphaerogypsina sp., } \\
\text { Operculina sp. ve Victoriella sp. gibi iri bentik foraminiferlerin dişında oldukça yaygın kırmızı ve yeşil }\end{array}$ \\
\hline Miyosen, Bentik foraminifer, Siirt, & algler de gözlenmiş̧tir. Bu veriler ışığında birimin yaş konağının erken-orta Miyosen olduğu belirlenmiştir. \\
\hline Paleoortam, Eskigarzan & $\begin{array}{l}\text { Bölgede yayılım gösteren bu karbonatlar çok sı̆̆, korunaklı ve orta-düşük enerjili bir lagün çökelme } \\
\text { ortamını karakterize ederler. }\end{array}$ \\
\hline
\end{tabular}

Doi: $10.24012 /$ dumf.1051467

\begin{tabular}{|c|c|}
\hline ARTICLE INFO & $A B S T R A C T$ \\
\hline Article history: & $\begin{array}{l}\text { The Miocene aged carbonate deposits outcropping around the Kurtalan district of Siirt province play an } \\
\text { important role in the geological evaluation of the region. This study is based on the evaluation of the unit, }\end{array}$ \\
\hline Received 7 October 2021 & which is lenticular within the Kayabağlar Formation and discriminates as the Eskigarzan Limestone \\
\hline Received in revised form 23 & Member, in the light of paleontological and sedimentological data. Along with serial sampling from four \\
\hline November 2021 & different localities taken from the Miocene aged Eskigarzan Limestone member, apart from large benthic \\
\hline Accepted 25 December 2021 & foraminifers such as Praebullalveolina curdica (Reichel), Sivasina egribucakensis Sirel and Özgen- \\
\hline Available online 31 December 2021 & Erdem, Sivasina batmanensis Sirel, Özgen-Erdem and Sinanoğlu, Androsina diyarbakirensis Sirel, Özgen- \\
\hline Keywords: & $\begin{array}{l}\text { Erdem and Sinanoğlu, Cyclorbiculina minima Sirel, Özgen-Erdem and Sinanoğlu, Amphistegina cf. } \\
\text { targioni Meneghini, Elphidium cf. crispum, Miogypsinoides sp., Rotalia sp., Sphaerogypsina sp., }\end{array}$ \\
\hline Miocene, Benthic foraminifera, & Operculina sp. and Victoriella sp. quite common coralline and green algae were also observed. In the \\
\hline $\begin{array}{l}\text { Siirt, Paleoenvironmental, } \\
\text { Eskigarzan }\end{array}$ & $\begin{array}{l}\text { light of these data, the age of the unit was determined as early-middle Miocene. These carbonates, which } \\
\text { are widespread in the region, characterize a very shallow, sheltered and medium-low energy lagoon } \\
\text { depositional environment. }\end{array}$ \\
\hline
\end{tabular}

* Sorumlu Yazar / Correspondence

Derya Sinanoğlu

derya.sinanoglu@batman.edu.tr 


\section{Giriș}

Güneydoğu Anadolu Bölgesi jeolojisinin ana yapısını, Arap ve Anadolu kıtalarının zaman boyutu içerisinde göreceli hareketleri kontrol etmiştir. Bu hareketlere bağlı olarak Arap kıtası üzerinde gelişen alçalıp yükselme hareketleri de sedimantasyonu kontrol etmiştir. "Neotetis Okyanusunun Geç Triyas'taki açılımı, Geç Kretase'de meydana gelen dalma-batma mekanizması ile kapanmaya başlaması ve Miyosen'deki kıta kıta çarpışması ile yitilmesi, sonrasında meydana gelen denizel ve gölsel havzalar ile çarpışma sonrası volkanizma Güneydoğu Anadolu Bölgesi ve Doğu Anadolu Bölgesinin jeolojisini şekillendiren en önemli jeolojik olaylardandır” [1]. Önceki dönemde aşınmış olan Toros yükselimi, Alt Eosen denizinin kuzeye doğru büyük transgresyonuyla geniş oranda kaplanmıştır. Orta Eosen-Oligosen döneminde bütün Güneydoğu Anadolu Bölgesi'nde sığlaşma olmuş ve devamlı karbonatlar çökelerek evaporitik ortamlar gelişmiştir. Alt-Orta Miyosen’de Arap kıtası ile Anadolu kıtası arasındaki sıkışma rejimi tekrar aktif hale gelmiş ve kuzey bölgelerde derin denizel türbiditik fasiyeste Lice Formasyonu çökelirken platform alanına doğru Fırat resifal karbonatları çökelmiştir. Üst Miyosen başlarken Toros kuşağına ait Bitlis-Pötürge allokton birlikleri yükselimini tamamlamış, denizel etki giderek kaybolarak karasal çökellerden oluşan Şelmo Formasyonu gelişmiştir (Şekil 1).
Oyuktaş Petrol Sahası'ndan Siirt'e kadar olan bölgede, Eosen-Oligosen ve Miyosen yaşlı evaporitli seviyeler, ayrıntılı bir çalışma yapılmazsa, aralarında diskordans olmasına rağmen yanlışlıkla tek bir birim gibi algılanmakta; Miyosen istifi içerisinde bulunan ve stratigrafik olarak iki farklı kireçtaşı aynı birim olarak yorumlanabilmektedir [2]. Miyosen dönemi boyunca Lice havzası olarak da nitelendirilen çalışma alanında Fırat Formasyonu bariyer resif olarak tanımlanmış, Lice Formasyonu'nun lagün eşleniği olan Kapıkaya Formasyonu ise Miyosen istifinin kıyı fasiyesini temsil eden klastik ve evaporitik istiften oluşmuştur. Ayrıca bu alanda yüzlek veren birimlerin kuyu verileri ile de korele edilerek bölgesel yorumlar yapıldığı Siyako vd., 2015 tarafından belirtilmiştir. Bölgede güvenlik problemleri nedeniyle önceden yapılmış paleontolojik çalışmalar yok denecek kadar azdır. Çalışmanın amacı, paleontolojik ve sedimantolojik olarak Miyosen yaşlı Fırat Formasyonu karbonatlarından yukarıda değinilen özellikleriyle ayrılan Eskigarzan Kireçtaşı Üyesi'nin iri bentik foraminifer cins ve türlerinin belirlenmesi, sedimantolojik incelemeleri, yaş konağının detaylı değerlendirilmesi ve bunlara dayandırılarak ortam yorumunun yapılmasıdır. $\mathrm{Bu}$ amaç doğrultusunda birimin harita alanında bulunan dört ayrı lokasyondan yirmi örnek alınmış ve bunlardan da kırk adet yönlü ince kesit yapılarak iri bentik foraminiferler tanımlanmıştır. Çalışma örnekleri Cumhuriyet Üniversitesi, Jeoloji Mühendisliği Bölümü Paleontoloji laboratuvarında depolanmaktadır. 


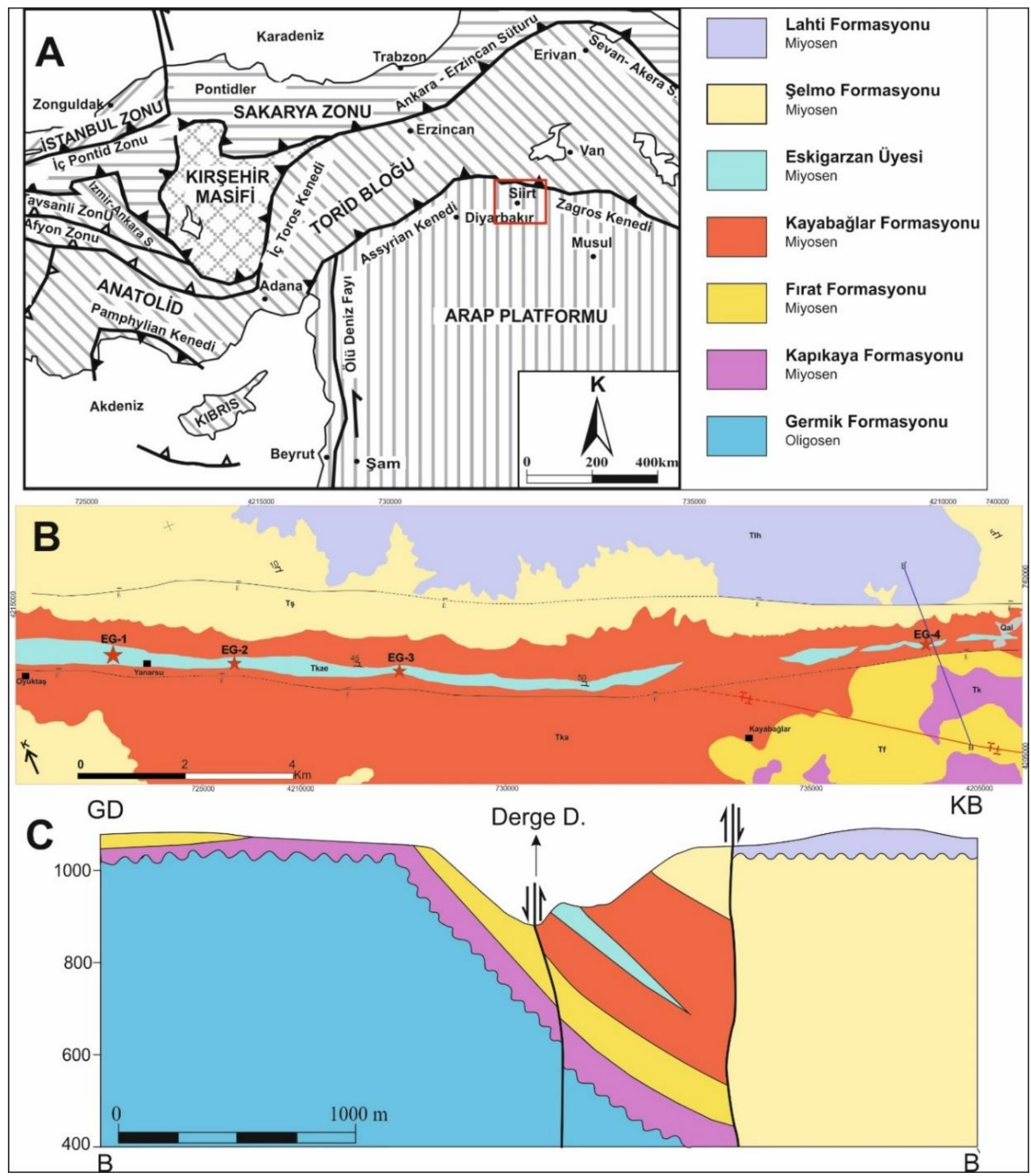

Şekil 1. A: Çalışma alanını bulduru haritası (Okay ve Tüysüz 1999'dan değiştirilerek alınmıştır); B: Çalışma alanı jeoloji haritası (değiştirilerek alınmıştır [2]); C: Derge Deresi’nde Eskigarzan Üyesi’nin tipik kesitine bakış.

\section{Bölgesel Jeoloji}

Siirt-Kentalan bölgesi ve çevresinde görülen stratigrafik istif, daha önce Siyako vd. [3] tarafindan belirtildiği gibi birbirlerinden bölgesel diskordanslarla ayrilan 4 dönemden oluşmaktadır:

1.Dönem (Maastrihtiyen-Paleosen); bu döneme ait en yaşlı birim, Gercüş Antiklinali çekirdeğinde mostra veren Maastrihtiyen yaşlı Garzan Formasyonu'dur. Tabanı görülmeyen birim, çeşitli fasiyeslerdeki sı̆ denizel karbonatlardan oluşur. Bu karbonatlar, dereceli olarak Maastrihtiyen-Paleosen yaşlı Germav Formasyonu'nun pelajik şeyl ve marn egemen, denizel litolojilere geçer. Formasyon, zaman içerisinde üste doğru regresif bir özellik kazanır. Bazı alanlarda Germav'ın üzerinde görülen ve Paleosen yaşlı denizel karbonatlardan oluşan birim Becirman Formasyonu olarak adlandırılmıştır. Sözü edilen regresyon sonucunda, yine Paleosen'e ait olan ve Antak 
veya Gercüş Formasyonu olarak adlandırılan fluviyal litolojiler çökelmiştir. Karasal birimlerle biten bu çökelme evresini, bölgesel bir aşınma evresi izlemektedir.

2.Dönem (Eosen-Oligosen) başlagıcında, Eosen'de gelişen bir transgresyonla, taban klastikleri ve sı̆̆ denizel karbonatlardan oluşan Hoya Formasyonu çökelmiştir. Eosen sonu Oligosen başlarında ise, bu denizin giderek sığlaşma ve kurumasıyla evaporitlerin yoğunlukta olduğu Germik Formasyonu gelişir. Daha sonra, yeni bir yükselme ve aşınma evresi görülür.

3.Dönem (Miyosen): Aşındırılmış yüzey üzerine, Erken Miyosen'de yeni bir transgresyon başlar. Bu defa, yine bir taban klastiği seviyesi olan Kapıkaya Formasyonu'ndan sonra, sığ bir karbonat platformunda Firat Formasyonu'nun sedimantasyonu görülür. Daha üstte, Fırat'la geçişli ve kesiksiz bir şekilde yer alan ve birbiriyle yanal geçişli olan iki ayrı formasyon görülmektedir: 1. Kısmen derin denizel Lice Formasyonu ve 2. Siğ denizel-evaporitik-karasal Kayabağlar Formasyonu. Orta-Geç Miyosen'de ortamın tedricen ve bütünüyle karasal ortama dönüşmesi, fluviyal fasiyeste olan Şelmo Formasyonu'nun gelişmesini sağlar. Böylece altta bir transgresyonla başlayan denizel dönem, üstte regresif olarak bu karasal çökelme ile sona erer.

4. Dönem (Pliyo-Kuvaterner): Stratigrafik olarak en üstte ve aşındırılmış yüzeyler üzerinde; Pliyosen yaşlı fluviyal Lahti Formasyonu, Kuvaterner'de ise bazalt, alüvyon taraçası ve alüvyon birimleri bulunmaktadır.

Çalışılan bölgede Oligosen yaşlı dolomit ve kumtaşı katkılı evaporitlerden oluşan Germik Formasyonu [4] üzerine denizel bir transgresyonla Miyosen istifi gelmektedir. Miyosen dönemi, transgresif olarak bir taban klastiği ile başlamakta, sı̆ denizel Fırat karbonatlarına geçmekte, evaporitik Kayabağlar Formasyonu ile devam ekmekte ve akarsu çökellerinden oluşan Şelmo Formasyonu ile son bulmaktadır. Kayabağlar Formasyonu içerisinde kireçtaşlarından oluşan merceksel Eskigarzan Üyesi ayrilabilmektedir (Şekil 1,2).

Transgresyonun başlangıcında enerjinin yüksek olmasına bağlı olarak kalınlığı 30 metreye kadar ulaşan bir taban konglomerası gelişmiştir. Bu birimin çeşitli adlamaları bulunmasına rağmen en doğru tanımlama Keskin [5] tarafindan Başur Konglomerası olarak yapılmıştır. Transgresyonun yavaş olduğu bazı kesimlerde çok incedir veya hiç çökelmemiştir [2]. Kiremit rengi, gri, kalın tabakalı, iri taneli kumtaşı ve çakıltaşlarından oluşmaktadır. $\mathrm{Bu}$ birim Siyako vd. [3] tarafindan Kapıkaya Formasyonu olarak adlandırılmış ve tarafımızdan da bu şekilde benimsenmiştir. Taban klastikleri üste doğru dereceli olarak sı ̆ denizel kireçtaşlarına geçmektedir. Fırat Formasyonu olarak adlandırılan [6] birim, yaygın olarak veya şeritler halinde haritalanmakta ve genellikle dayanımlı olan kireçtaşı litolojisi nedeniyle sarp tepelerde görülmektedir. Çalışılan alanda kalınlığı 50 metreye kadar çıkmaktadır. Çoğunlukla yama resifi ve resif yakını fasiyes özellikleri de olan sı ̆ denizel karbonatlardan oluşur, krem-bej renkli, orta-çok kalın veya som tabakalıdır. Kireçtaşları mikroskopik olarak, biyoklastik tanetaş1/istiftaşı şeklinde tanımlanırlar. Kireçtaşlarının tipik özelliği mercan kolonileri ve kırmızı alglerin yanısıra makro ve mikro fosilleri de içermesidir [2].

Oyuktaş Sahası'ndan başlayarak Siirt'e kadar olan bölgede mostra veren, altta Firat ve üstte Şelmo Formasyonu ile dereceli geçişli olan birim, çok sığ denizel, evaporitik ve fluviyal bir ortam ürünüdür. Birimin toplam kalınlığ 1200 400 metre kadardır.

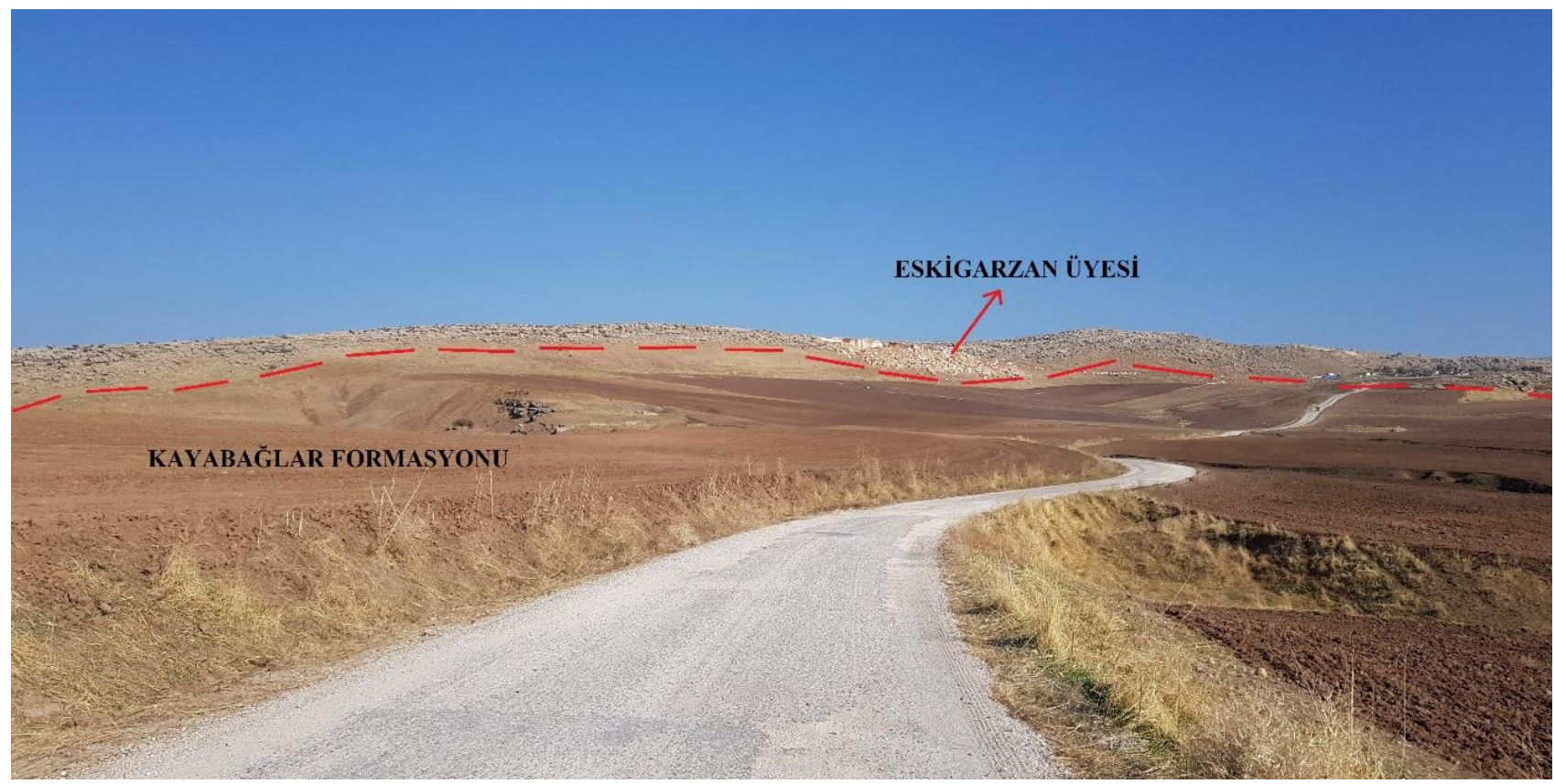

Şekil 2. Yanarsu yakınlarındaki Eskigarzan Üyesi ve Kayabağlar Formasyonu'nun görünümü 
Bölgede karasal evrelerde zaman zaman deniz istilaları olmuş, marn ve şeyllerin yanı sıra merceksel görünümde (Şekil 2) sı̆̆ denizel kireçtaşı seviyeleri de gelişerek bunlar ilk defa Bolgi [4] tarafindan Eskigarzan Kalkeri olarak adlandırılmıştır.

$\mathrm{Bu}$ çalışmanın asıl konusunu oluşturan Eskigarzan Kireçtaşı Üyesi litolojik olarak Fırat Formasyonu kireçtaşlarına çok benzemesine rağmen, tipik olarak hiçbir yerde taban klastiği gözlenmez. Mostrada kuzeybatıda Oyuktaş Köyü'nden Güneydoğu'da Kurtalan kuzeyine kadar olan alanda bir şerit şeklinde, merceksel şekilde haritalanmıştır (Şekil 1,2). Birim sı̆̆ denizel biyoklastik ve sert-masif kireçtaşlarından oluşur, beyaz-gri renkli, ortaçok kalın veya som tabakalıdır, bölgede kalınlıkları 35 metreye kadar ulaşır.

Kayabağlar Formasyonu ortamın bütünüyle karasal ortama dönüşmesi sonucunda tedricen Şelmo Formasyonu'na [4] geçer. Fluviyal klastiklerden oluşan bu birim ile Miyosen istifi tamamlanmış olur ve daha üste açısal diskordanslı olarak yine fluviyal çökellerden oluşan Lahti Formasyonu [4] gelir.

\section{Eskigarzan Seri Örnekleri}

$\mathrm{Bu}$ örnekler, 1/25.000 ölçekli M 47-a2 paftasında, Yanarsu Köyü ile Kurtalan ilçesi arasında yer alır. Yaklaşık kalınlığ 1 20-35 m arasında değişen formasyonda dört ayrı noktadan 20 adet örnek alınmış olup, bunlardan da 40 adet yönlü ince kesit üzerinde paleontolojik çalışmalar

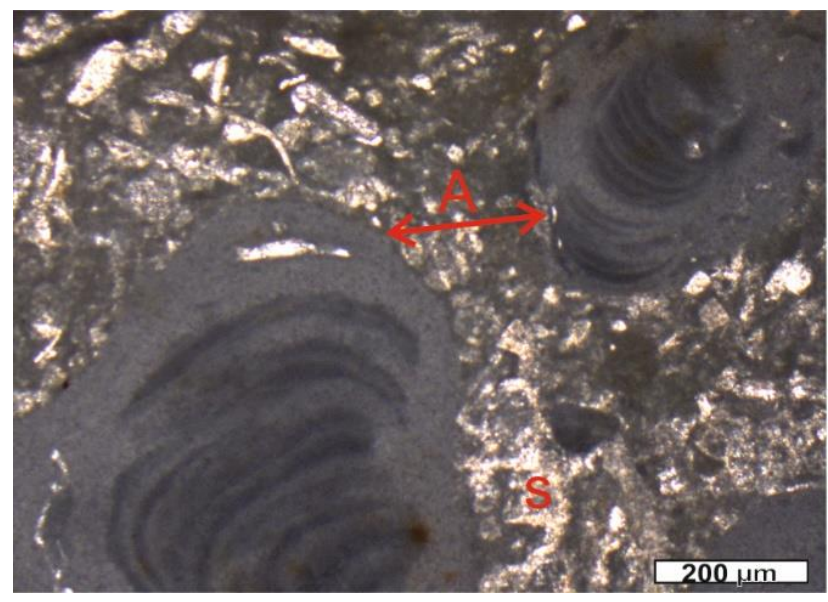

yapılmıştır. Araziden alınan örnekler sert kayalardan oluştuğu için sert kayaç örnekleri öncelikli olarak laboratuvardaki Petrocat makinasına yerleştirilerek birkaç mm kalınlıkta kesilmiştir. Lam üzerine yapışacak yüzeyin bir cam levha üzerinde aşındırıcı demir tozlarıyla pürüzleri giderilmiş olup benzer şekilde lamın yapışacak yüzeyi de demir tozunda aşındırılır. Isıtıcı yardımıyla kanada balzamı ile örnek hava kalmayacak şekilde cama yapıştırılır. Kısa bir müddet soğuma sonrasında örnekler inceltilir. Mikroskop altında incelenebilecek kalınlığa getirmek için ise lama yapışmış örnek, cam üzerinde ince demir tozları ile iyice aşındırılır ve istenilen kalınlıkta ince kesit alımı sağlanmış olur. Alınan örnekler harita üzerinde ancak bir nokta olarak gösterebilecek mostralarda seri olarak tabandan tavana doğru alınmıştır. Eskigarzan Kireçtaşı Üyesi az veya çok belirgin, kalın katmanlı, bol fosilli, çok sert kırıklı ve çatlaklı, beyaz, gri veya pembemsi renkli özellikleriyle ayırt edilir.

EG-1: 38.042955D; 41.551990K: Yanarsu Köyü yaklaşık $500 \mathrm{~m}$ batısında mermer ocağını da içine alan bu kesitin (20$25 \mathrm{~m}$ ) mikroskobik incelemelerinde tabandan itibaren bol fosilli, az intraklast taneli ve yer yer demiroksit kalıntıları olduğu gözlenmiştir. Dunham (1962) sınıflamasına göre istiftaşı niteliğinde olan kayaç mikrit ve sparit bağlayıcılıdır. Fosil içeriği \%70-80, sparit bağlayıcı \%1520 ve mikrit bağlayıcı \%10-15 civarındadır. Fosil içeriği açısından oldukça zengin porselen kalker ve hiyalin kalker bentik foraminiferler, kırmızı alg, yeşil alg, ekinit, bryzoa ve mercan içerir (Şekil 3).

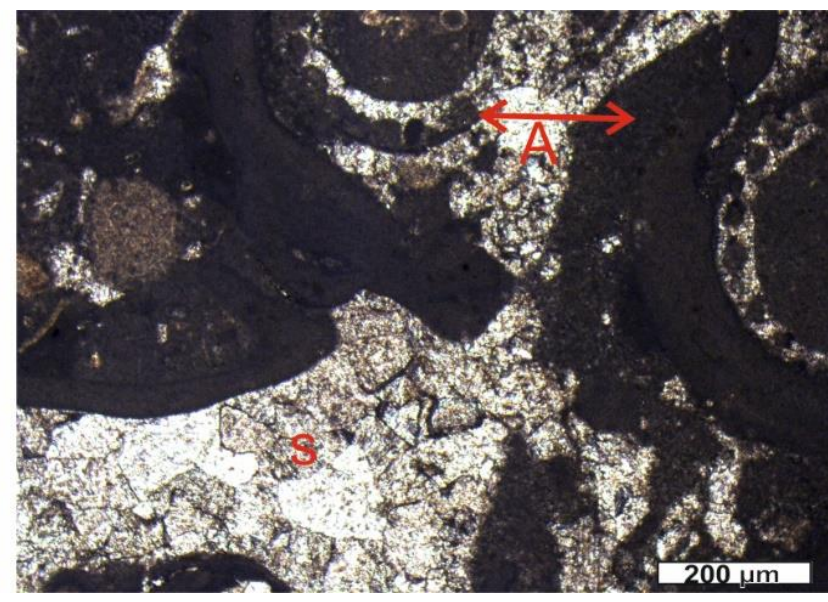

Şekil 3. EG-1 karbonat mikrofasiyesi (A: alg; s: sparit bağlayıcı)

EG-2: 38.033260D; 41.575624K: Yanarsu Köyü yaklaşık $1,5 \mathrm{~km}$ doğusunda yer alan kesitin (30-32m) mikroskobik incelemelerinde tabandan itibaren bol fosilli, bol algli, sparit ve mikrit bağlayıcıdan oluştuğu gözlenmiştir. Fosil içeriği $\% 75-85$, sparit bağlayıcı $\% 10-15$ ve mikrit bağlayıcı
\%5-10 civarındadır. Dunham (1962) sinıflamasına göre kayaç istiftaşı niteliğindedir. İnce kesitler foraminifer içeriği olarak Soritid formların yanı sıra Textularid ve Miliolidal formlar açısından zengindir. Yeşil alglerden ziyade kırmızı algler baskınlık kurar (Şekil 4). 

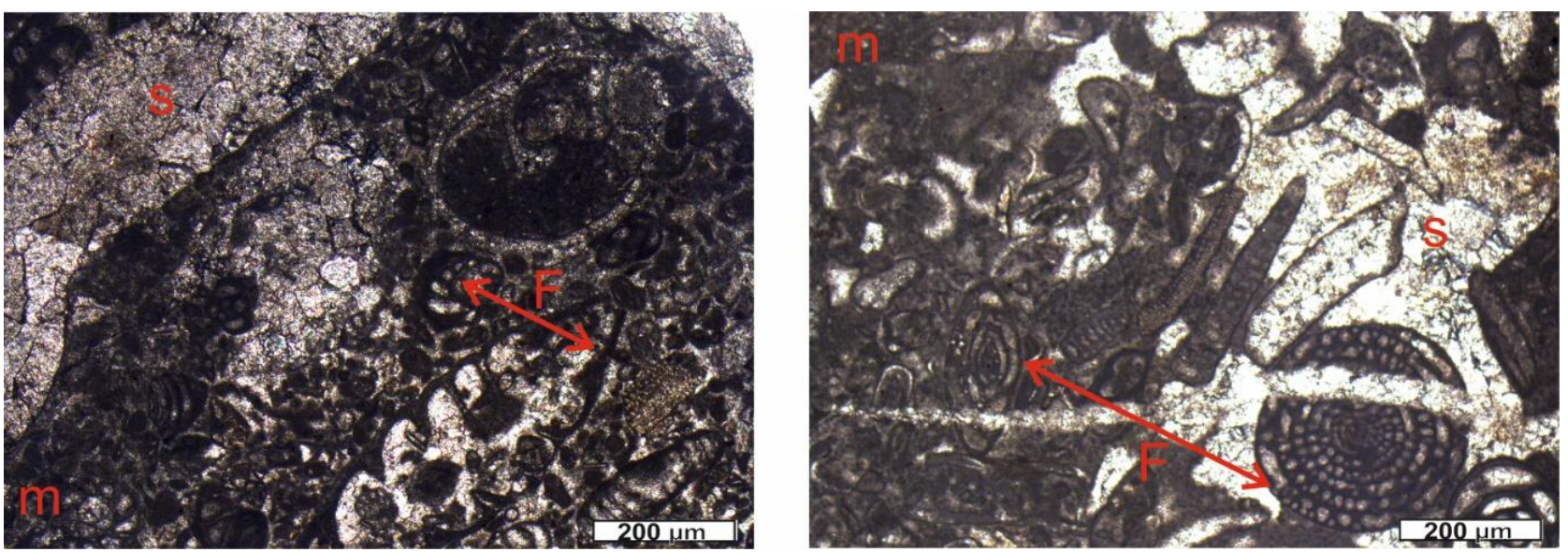

Şekil 4. EG-2 karbonat mikrofasiyesi (m: mikrit bağlayıc1; s: sparit bağlayıc1; F: fosil)

EG-3: 38.019505D; 41.606977K: Kapıkaya Köyü 200 m güneyinde yer alan kesitin (30-35m) mikroskobik incelemelerinde tabandan itibaren bol fosilli, bol kırmızı algli, az sparit ve daha çok mikrit bağlayıcıdan oluştuğu gözlenmiştir. Fosil içeriği \% 75-85, sparit bağlayıcı \%15-20 ve mikrit bağlayıcı $\% 5$ civarındadır. Mikrit bağlayıcı

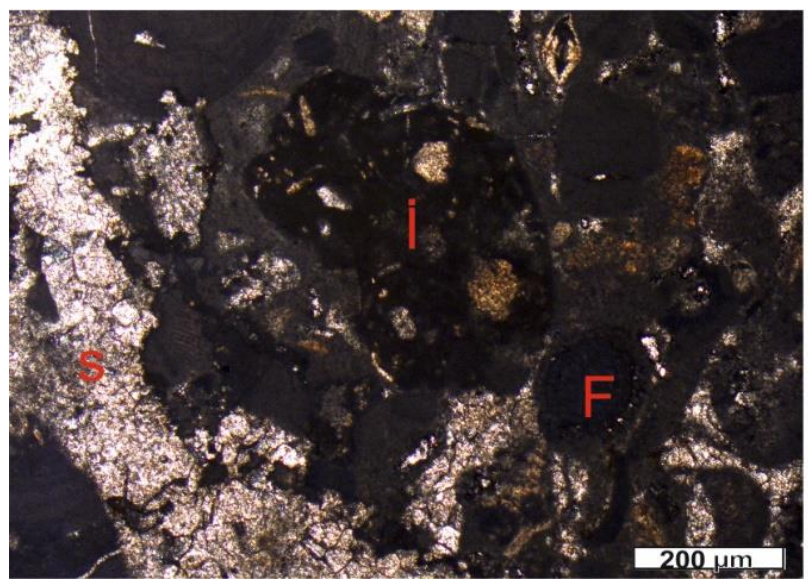

genellikle ikincil olarak ince çatlakların içerisinde gözlenir. Dunham (1962) sınıflamasına göre tanetaşı kategorisinde tanımlanan kayaçta özellikle hiyalin kavkılı Operculina formları ve kırmızı alglerin bolluğu oldukça dikkat çekicidir (Şekil 5).

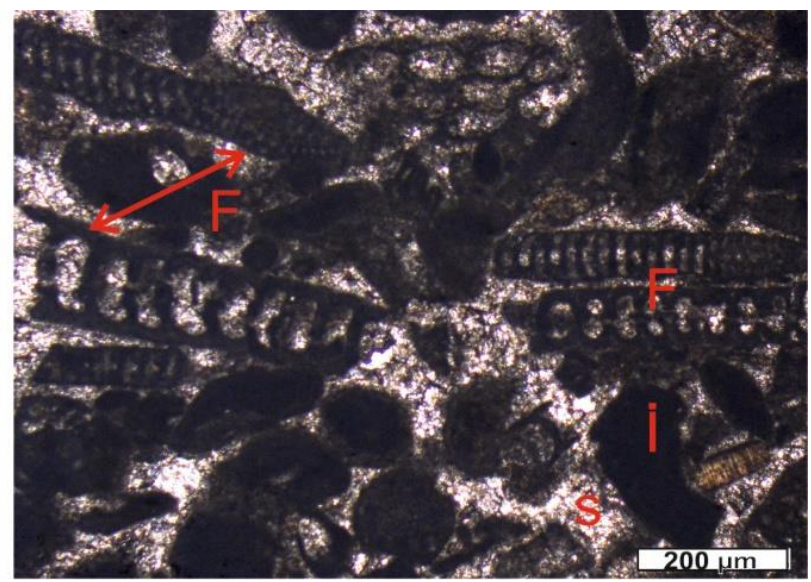

Şekil 5. EG-3 karbonat mikrofasiyesi (İ: intraklast; s: sparit bağlayıc1; F: fosil)

EG-4: 37.986558D; 41.706580K: Kurtalan çimento fabrikası 2500 m kuzeyindeki Derge Dere kuzey yamacinda alınan kesitin mikroskobik incelemelerinde tabandan itibaren bol fosilli, bol kırmızı algli ve daha çok mikrit bağlayıcıdan oluştuğu gözlenmiştir. Fosil içeriği \%60-65 sparit bağlayıcı $\% 5$ ve mikrit bağlayıcı $\% 35$ civarındadır. Demiroksit kalıntıları bu kesitte daha fazladır ve kayaç istiftaşını karakterize eder. Soritid formlar ve alglerin baskınlığı daha fazladır (Şekil 6). 

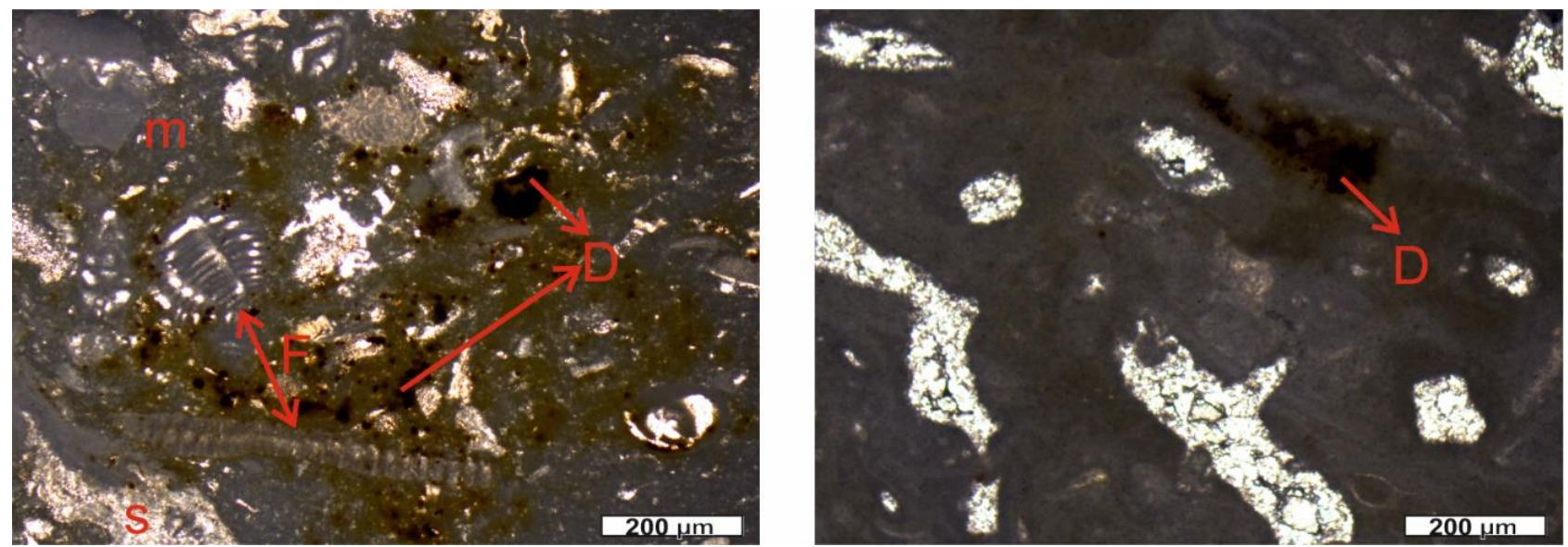

Şekil 6. EG-4 karbonat mikrofasiyesi (D: demiroksit; s: sparit bağlayıc1; m: mikrit bağlayıc1; F: fosil)

\section{Ortamsal Yorum}

"Oligo-Miyosen boyunca, Akdeniz bölgesi ve Orta Doğu genellikle daha büyük bentik ve planktonik foraminiferler açısından zengin, sı̆̆ deniz çökellerinin birikmesiyle karakterize edilmiştir" [7].

Çoğu bentik organizmanın göreceli olarak sı ̆ sularda ve sakin ortamlarda yaşadığı bilinmektedir. Bölgede yayılım gösteren Miyosen karbonatları da porselen-hiyalin kavkılı foraminiferler ve kırmızı algler bakımından zenginliği ile tipiktir. Hauerinid türlerden Sivasina egribucakenssis, Sivasina batmanensis ve Soritid türlerden Cyclorbiculina minima, Androsina diyarbakirensis oldukça sığ, korunaklı ve lagünel ortamları karakterize ederler [8] (Şekil 7).
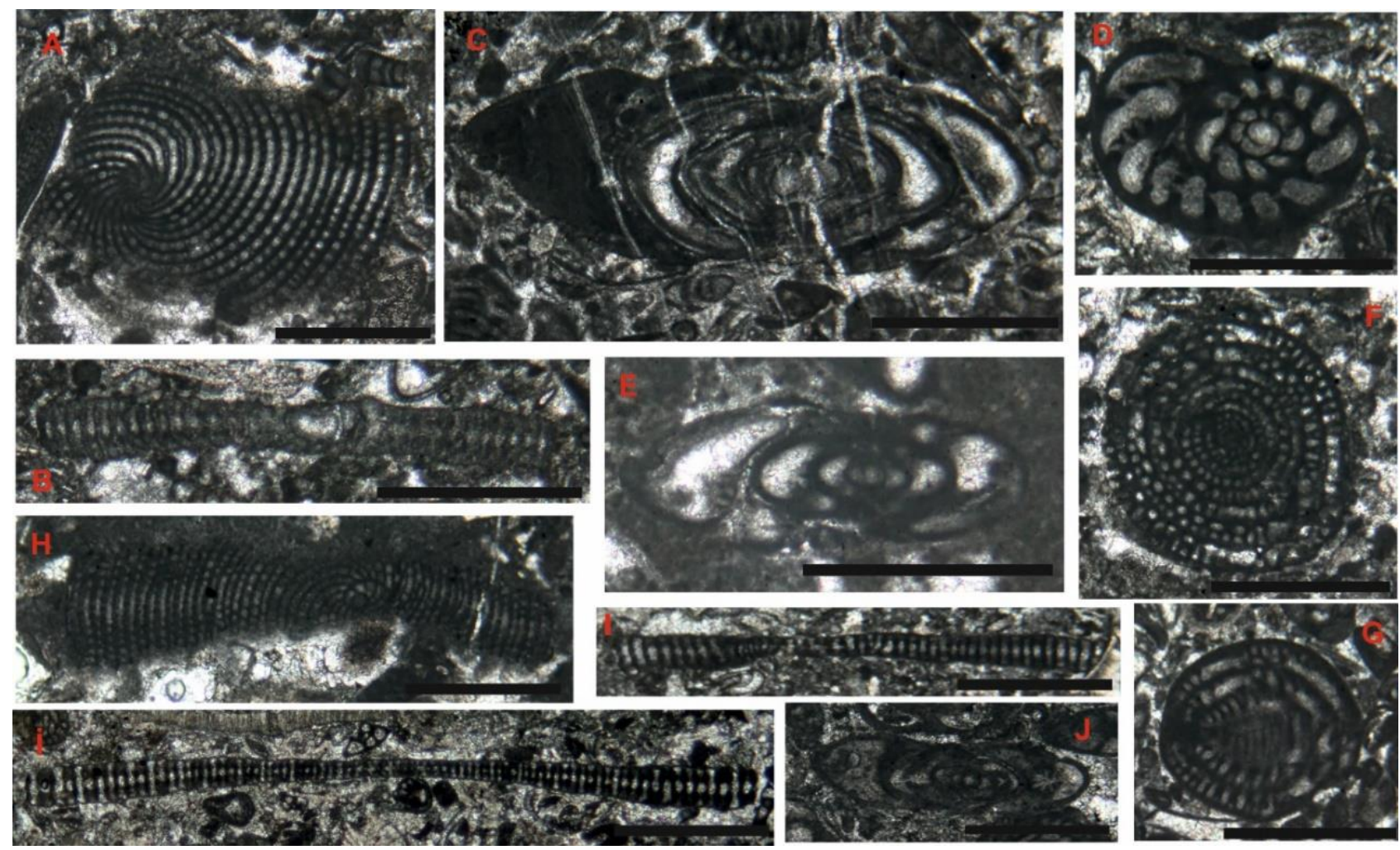

Şekil 7. Miyosen karbonatlarından tanımlanan foraminifer türleri: A, B. Androsina diyarbakirensis; C, D. Sivasina batmanensis; E, J. Sivasina egribucakensis; F, G. Praebullalveolina curdica; H, I, I. Cyclorbiculina minima.

(ölçek: $1000 \mu \mathrm{m})$

Siğ ortamlardan daha derin ortamlara doğru foraminifer kavkı yapısındaki değişimleri gözlemlemek mümkündür [9]. Amphistegina ve Operculina fotik bölgenin tabanı veya çevresinde yaygın olarak birlikte yaşayabilirler. Soritid formlardan bazıları ve Operculina'lar Oligo-Miyosen döneminde enerjinin düşük olduğu yumuşak zeminlerde yaşamlarını sürdürmüşlerdir [9]. Güncel iri bentik foraminiferler üzerinde yapılan çalışmada Operculina'nın kalın kavkılı ve sıkı sarılımlı olanları sığ derinliklerinde (20-40 m derinlikte) yaşarken, ince kavkılı ve gevşek 
sarılımlı olanları euphotic zonda $(120 \mathrm{~m})$ baskın olduğu gözlenmiştir [10]. Operculina ve Miogypsinoides gibi hiyalin kavkılı formlar fotik zonun daha derin kısımlarınıorta ramp ve orta 1şık koşullarını işaret eder [11]. Amphisteginidlerin ise genel olarak tuzluluk tolerans1 düşük ve yüksek enerjili ortamlarda, 30 metreden sı̆̆ derinliklerde [12] yaşadıkları bilinmektedir (Şekil 8).
Porselen kavkılı büyük bentik foraminiferler fotik bölgenin üst kısmında karbonat platformları geliştirirler [13]. Kırmızı algler de fotik bölge çökellerinden kaydedilen en bol bileşenlerden biridirler [14]. Genel olarak ise birimin düşük-orta enerjili, normal tuzluluktaki sığ denizel karbonat ortamlarını yansıtmaktadır.

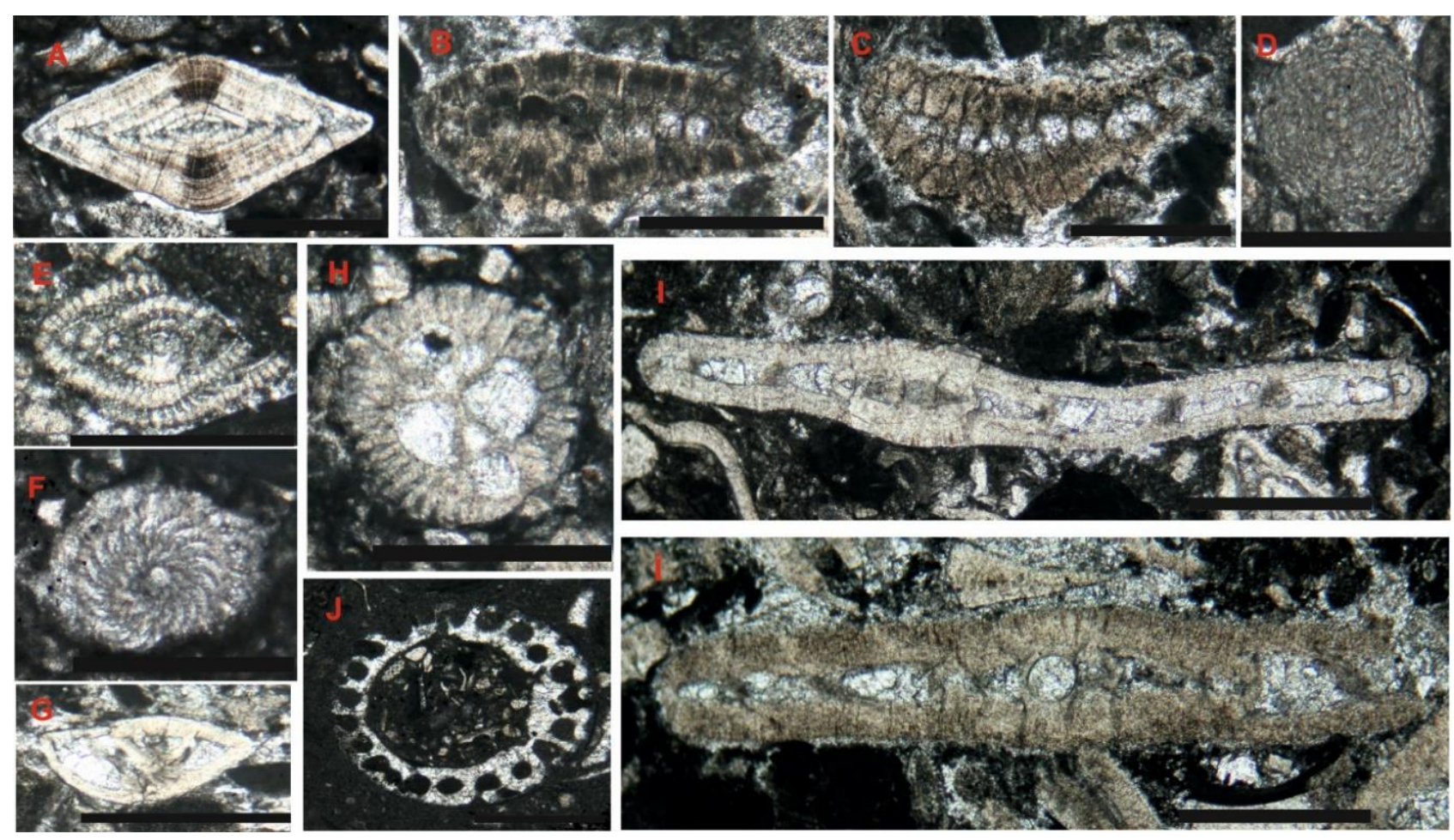

Şekil 8. Miyosen karbonatlarından tanımlanan foraminifer türleri: A. Amphistegina cf. targioni; B, C. Miogypsinoides sp.; D. Sphaerogypsina sp.; E, F. Elphidium cf. crispum; G. Rotalia sp.; H. Victoriella sp.; I, İ. Operculina sp.; J. Alg. (ölçek: $1000 \mu \mathrm{m}$ )

\section{Tartışma ve Sonuçlar}

Çalışılan alan ve çevresinde Miyosen dönemi boyunca Neotetis Okyanusu aktif kıta kenarında yer almaktadır. $\mathrm{Bu}$ nedenle, Neotetisin kapanma sürecinin izlerini stratigrafik ve paleontolojik olarak gözlemlemek mümkündür. Eskigarzan Kireçtaşı Üyesi litolojik benzerlik nedeniyle Frrat Formasyonu'nun kireçtaşlarıyla karıştırılmaktadır. Bölgenin petrol üretimi için önemi göz önüne alındığında stratigrafinin doğru bir şekilde ortaya konmasının önemi de ortaya çıkmaktadır. Eskigarzan Üyesi'nin kaya-stratigrafik olarak Firat Formasyonu'nun altında yer alan Kayabağlar Formasyonu içerisinde merceksel olarak bulunduğu arazide çok net gözlenmekle beraber jeolojik haritada da gösterilmiştir. Ayrıca bölgesel olarak belirtmek gerekirse, Firat Formasyonu'ndan sonra, Lice-Kulp civarında Miyosen bindirmesinin öneyinde gelişen ve Lice iç çukuru olarak adlandırılan [15-16] dar bir kuşakta derin denizel türbiditik fasiyeste Lice Formasyonu çökelirken, aynı dönemde doğu ve güneydoğuya gidildikçe Oyuktaş-Kurtalan-Siirt bölgesinde evaporitiksı ̆̆ denizel-karasal bir ortamda Kayabağlar Formasyonu ve Eskigarzan Üyesi gelişmiştir. Siirt ve çevresindeki Miyosen yaşlı Eskigarzan karbonatlarında tanımlanan formlar ayrıca birçok bölgenin de stratigrafik ve paleontolojik ölçekte korelasyonunun sağlanmasında oldukça önem arz eder. Türkiye ve Dünya geneline baktığımızda farklı bölgelerde yapılan çalışmalarda benzer foraminifer ve alg topluluklarının, benzer çökelme ortamlarını karakterize ettiği gözlenmiştir. [178-18], benzer topluluğu Erken Miyosen'de Türkiye'de; [19-20], Miyosen'de İran'da; [21] Miyosen'de Umman'da benzer topluluklardan bahsetmişlerdir.

Tüm kesit boyunca porselen kalker ve hiyalin kavkılı bentik foraminiferlerin yanı sıra yeşil ve kırmızı alglerin baskınlığıyla birimin yaş konağı Miyosen'i işaret eder.

Eskigarzan Üyesi'nin taban seviyesindeki baskın faunasını geniş, yassı ve porselen kalker kavkılı Androsina, Sivasina, Praebullalveolina, Cyclorbiculina cins ve türleriyle birlikte yeşil alglerin varlığı oluşturur. $\mathrm{Bu}$ formlar daha sı ̆̆, sakin ve düşük enerjili ve korunaklı ortamın göstergeleridir. Üst kesimlere doğru ise baskın faunasını geniş, iri ve delikli hiyalin kavkılı Operculina, Amphistegina, Miogypsinoides ve Elphidium, Rotalia cins ve türlerinin yanı sıra kırmızı algler oluşturur. Bu formlar ise biraz daha derin ve çalkantılı ortamları işaret eder. $\mathrm{Bu}$ veriler ışığında bölgedeki Miyosen yaşlı bu 
karbonatların sedimantolojik ve paleontolojik olarak incelenmesiyle birimin normal tuzlulukta olan sı̆̆ ve korunaklı bir lagün ortamında çökeldiği sonucuna var1labilir.

\section{Teşekkür}

$\mathrm{Bu}$ çalışmada katkılarında dolayı Prof. Dr. Nazire ÖZGEN-ERDEM, Muzaffer SIYAKO, Dr. Öğr. Üyesi Salih DINÇ, ve Şafak ÖZSARAÇ’a teşekkür ederim. Makalenin değerlendirme sürecindeki katkılarından dolayı hakemlere teşekkürlerimi sunarım.

\section{Kaynaklar}

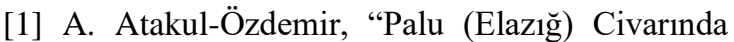
Yüzeylenen Bitlis Masifi Üst Triyas Karbonatlarının Foraminifer Biyostratigrafisi, Mikrofasiyes Analizleri ve Çökelim Ortamları", Türkiye Jeoloji Bülteni, 62:1-16, 2019.

[2] M. Siyako, H. Şeker, İ., Bahtiyar, İ. Özdemir, S.F. Kılınç, D. Arslan, A. Karaçay, S. Özsoy, ve B. İşdiken, "Batman, Beşiri, Kurtalan, Raman ve Gercüş civarının jeolojisi ve hidrokarbon olanakları", TPAO Arama Dairesi Başkanlığı Arşivi, yayınlanmamış teknik rapor, 5546, 132 s, 2015.

[3] M. Siyako, İ. Bahtiyar, T. Özdoğan, İ. Açıkbaş, Ö.Ç. Kaya, "Batman Çevresinde Mostra Veren Birimlerin Stratigrafisi”, TPAO Araştırma Merkezi, Rapor no. 5463, 154s. Yayımlanmamış, 2013.

[4] T. Bolgi, "V. Petrol Bölgesi seksiyon ölçmeleri AR/TPO/261 no'lu saha ile Reşan-Dodan aras1 batısındaki sahanın strüktürel etüdleri”, TPAO Arama Grubu, Rapor no. 162, 52s, 1961.

[5] C. Keskin, "Eski Garzan antiklinalinde Miyosen formasyonlarının stratigrafisi", TPAO Arama Grubu Rapor no. 431, 12 s, 1968.

[6] M. Peksu, "Proposed rock unit nomenclature, Petroleum District V. and VI, SE Turkey”, TPAO Arama Grubu Rapor no. 5158, 1969.

[7] H. Yazdi-Moghadam, A. Sadeghi, M.H. Adabi, "Foraminiferal biostratigraphyof the lower Miocene Hamzian and Arashtanab sections (NW Iran) northern margin of the Tethyan", Geobios, 51: 211-246, 2018.

[8] E. Sirel, N. Özgen-Erdem ve D. Sinanoglu, "Foraminiferal Description of the Miocene ShallowWater Limestone from the Diyarbakır and Siirt Areas of Southeast Turkey" Journal of the Palaeontological Society of India, Volume 65(2):31, 131-148, 2020.

[9] L. Hottinger, "Processes determining the distribution of larger foraminifera in space and time. In: Meulenkamp JE (ed) Reconstruction of marine paleoenvironments", Utrecht Micropaleontol Bull. 30:239-253, 1983.
[10] E.K. Yordanova ve J. Hohenegger, "Morphoclines of living operculinid foraminifera based on quantitative characters", Micropaleontology, 50(2), 149-177, 2004.

[11] D. Bassi, L. Hottinger, J.H. Nebelsick, "Larger foraminifera from the Late Oligocene of the Venetian area, north-eastern Italy", Palaeontology, 50:845-868, 2007.

[12] P. Hallock, "Symbiont bearing foraminifera. In: Sen Gupta BK (ed) Modern foraminifera" Kluwer, Dordrecht, pp 123-139, 1999.

[13] J. Hohenegger, "Coenoclines of larger foraminifera" Micropaleontology, 4(Suppl 1):127-151, 2000 .

[14] J.H. Nebelsick, D. Bassi, J. Lempp, “Tracking paleoenvironmen-tal changes in coralline algaldominated carbonates of the Lower Oligocene Calcareniti di Castelgomberto formation (Monti Berici, Italy)", Facies 59:133-148, 2013.

[15] M. Rigo de Righi ve A. Cortesini. "Gravity tectonics in foothills structure belt of southeast Turkey", American Association of Petroleum Geologists Bulletin, 48 (12): 1911-1937, 1964.

[16] O. Sungurlu, "VI. Bölge kuzey sahalarının jeolojisi”, Türkiye 2. Petrol Kongresi Tebliğleri, 85-107, 1974.

[17] E. Sirel, N. Özgen-Erdem ve Ö. Kangal, "Systematics and biostratigraphy of Oligocene (Rupelian-Early Chattian) foraminifera from lagoonalvery shallow water limestone in the eastern Sivas Basin (central Turkey)", Geologia Croatica, 66(2): 83-109, 2013.

[18] U. Iş1k ve A. Hakyemez, "Integrated Oligocenelower Miocene larger and planktonic foraminiferal biostratigraphy of the Kahramanmaraş Basin (Southern Anatolia, Turkey)", Turkish Journal of Earth Sciences, 20(2), 185-212, 2011.

[19] A. Rahmani, H. Vaziri-Moghaddam, A. Taheri ve A. Ghabeishavi, "A model for the paleoenvironmental distribution of larger foraminifera of OligoceneMiocene carbonate rocks at Khaviz Anticline, Zagros Basin, SW Iran", Historical Biology, 21(3-4), 215-227, 2009.

[20] M.A. Dill, H. Vaziri-Moghaddam, A. Seyrafian, A. Behdad ve R. Shabafrooz, "A review of the OligoMiocene larger benthic foraminifera in the Zagros basin, Iran; New insights into biozonation and palaeogeographical maps", Revue de Micropaléontologie, 66, 100408, 2020.

[21] J. Serra-Kiel, A. Gallardo-Garcia, P. Razin, J. Robinet, J. Roger, C. Grelaud, S. Leroy ve C. Robin, "Middle Eocene-Early Miocene larger foraminifera from Dhofar (Oman) and Socotra Island (Yemen)", Arab J Geosci 9:344, 2016. 


\section{Taksonomik Liste}

Androsina diyarbakirensis, Sirel, Özgen-Erdem ve Sinanoğlu, 2020

Androsina diyarbakirensis, Sirel vd., 2020, Pl. V, figs. 19.

Tanım: Kavkı flabelliform ve büyük olup, kavkı çapı yaklaşık 2,5mm'dir. Kavkı diğer archaiasinid formlarda olduğu gibi porselen kalkerdir.

\section{Cyclorbiculina minima, Sirel, Özgen-Erdem ve Sinanoğlu, 2020}

Cyclorbiculina minima, Sirel vd., 2020, Pl. VI, figs. 1-7.

Tanım: Kavkı küçük, ince, diskoidal şekilli ve kavkı duvarı porselen kalkerdir. Küresel ilk locayı 4-5 tur planispiral-involüt sarılım takip eder.

Sivasina batmanensis, Sirel, Özgen-Erdem ve Sinanoğlu, 2020

Dendritina sp. Betzler vd., 1997, p. 212, Fig. 3a-e.

Sivasina batmanensis, Sirel vd., 2020, p. 4, Fig. 1-9.

Tanım: Kavkı merceksi, büyük ve şişkin olup, kavkı çap1 1,25-2,1 mm arasındadır. Locaları daha uzun ve daha büyüktür. Kavkı duvarı deliksiz ve porselen kalkerdir.

Sivasina egribucakensis, Sirel and Özgen-Erdem, 2013

Dendritina rangi d'Orbigny, Amirsahkarami et al., 2010, p. 81, pl. 2, Fig. 2.

Sivasina egribucakensis Sirel and Özgen-Erdem, 2013, p. 96, pl. IV, Figs. 1-14; pl. V, Figs. 1-10; pl. VI, Figs. 1-6; Fig $6 \mathrm{G}, \mathrm{H}$.

Dendritina cf. rangi d'Orbigny, Gedik, 2014, p. 98, pl. 9, Figs. 6-8.

Tanım: Kavkı büyük ve şişkin olup, kavkı çapı 0,66-0,9 $\mathrm{mm}$ arasındadır. Kavkı duvarı deliksiz ve porselen kalkerdir. Sarılım erken evrede planisripal-involüt, yetşkim evrede ise planispiral-evolüttür.

\section{Praebullalveolina curdica (Reichel, 1936-37)}

Borelis melo (Fichtel and Moll) curdica (Reichel), Robert et al., 2006, pl. 1, Figs. 4, 5.

Borelis curdica (Reichel), Yazdi-Moghadam et al., 2018, p. 236, Fig. 11.

Praebullalveolina curdica, Sirel, Özgen-Erdem ve Sinanoğlu, 2020, Fig. 4A-C; Pl. I, figs. 1-10; Pl. II, figs. $1-6$.

Tanım: Kavkı küçük ve küresel olup, ekvatoryal çap 0,61,1 mm arasındadır. İlk loca oldukça küçüktür (0,07-0,08 mm). Eksenel kesitlerde localar kalın septalar ile bölünerek, özellikler tanımlamalarda önemli nir gösterge olan 'Y-shape' yapısını oluştururlar. Kavkı duvarı deliksiz ve porselen kalkerdir.

\section{Elphidium crispum (Linnaeus 1758)}

Elphidium crispum (Linnaeus), Hottinger, Reiss and Langer, 2001, p. 28, pl. 10, Figs. 4, 5, 6 and 7.

Elphidium crispum (Linnaeus), Yazdi-Moghadam et al., 2021, Fig 11, e, f.

Tanım: Kavkı hiyalin kalker olup, küresel ve küçük bir ilk locaya sahiptir. Sütur çizgileri oldukça kavislidir. Kavkı dikey kanallarla bölünmüştür. 